\title{
Development of people with disabilities (PWD)-friendly module for bakery production
}

\author{
1,*Mahmood, A., ${ }^{1}$ Mohamad, N.J., ${ }^{1}$ Sarbon, N.M., ${ }^{1}$ Mohd Zin, Z., ${ }^{1}$ Azlin-Hasim, S. and \\ ${ }^{2}$ Wan Rosli, W.I. \\ ${ }^{1}$ Faculty of Fisheries and Food Science, Universiti Malaysia Terengganu, 21030 Kuala Nerus, Terengganu, \\ Malaysia \\ ${ }^{2}$ School of Health Science, Universiti Sains Malaysia Health Campus, 16150 Kubang Kerian, Kota Bharu, \\ Kelantan, Malaysia
}

\begin{abstract}
Article history:
Received: 20 March 2021

Received in revised form: 29

April 2021

Accepted: 28 June 2021

Available Online: 6 March 2022
\end{abstract}

\section{Keywords:}

Training module,

PWD,

Bakery products,

Training skills,

Community-based program

\section{DOI:}

https://doi.org/10.26656/fr.2017.6(2).190

\begin{abstract}
People with disabilities (PWDs) are often excluded from the surrounding community due to their physical or mental health deficiencies. This special group needs special care to enable them to have equal opportunities in all aspects. This project aims to develop PWDfriendly modules specially designed to train and build PWD skills on basic bakeries products including pizza bread, red bean bun, sausage bread and "paung" bread (plain bun). Considering their disabilities in reading for most of the PWD, the modules are more focused on visual presentations rather than instructions. To access the functioning of the modules, direct practical experience was conducted in a series of workshops in community-based rehabilitation (CBR). The effectiveness of the modules was evaluated in terms of their feasibility and acceptability including colour scheme, language used, skills and knowledge enhancement, user friendly and attractiveness level. Most of the respondents either strongly agreed or agreed on the components of feasibility and acceptability of the PWD-friendly modules. The modules were said to user friendly, helpful and recommended to be used by others. Not only these modules could improve the PWD skills on bakeries products for commercialization but also increased their motivation and self-confidence to get involved with the community.
\end{abstract}

\section{Introduction}

According to the Persons with Disabilities Act, 2008, "OKU or disabled is defined as a person who has long term physical, mental, intellectual or sensory impairment which in interaction with various barriers may hinder their full and effective participation in society" (Social Welfare Department, 2021). Inability to live independently is the main concern, especially for the young age to prepare them for greater job opportunities. The Human Rights Commission of Malaysia (Suhakam) said People with Disabilities (PWD) in Malaysia continue to face inequalities in their aspects of life including employment, education and health, resulting in being marginalized from social participation (Babulal, 2017).

People with disabilities usually face unprecedented challenges in seeking jobs. The unemployment rate of PWD remains significantly higher than those without disabilities. National social policy that was launched by the Malaysian government on 19 August 2003 proposed that one of the agendas is to ensure disabled persons for better empowerment by providing them with suitable social support systems including knowledge and training (Department of Social Welfare, 2009). In order to legally recognize the rights of $\mathrm{PWD}$, a law known as the Person with Disabilities Act (PWDA) was came into force in 2008 to provide PWD in Malaysia with registration, protection and rehabilitation, as well as their development and wellbeing (Wahab and Ayub, 2016).

It is important to consider many barriers and difficulties in order to ensure that PWD can maximize their access to the learning process. It is also challenging for us to expect those with disabilities to access the same learning and social opportunities as those without disabilities (Jackson et al., 2009). Due to PWDs normally having problems in mobility or intellectual impairment, thus they do not go to school in their childhood or only go for a few months or years on an irregular basis. Thus, most of them are illiterate and need special instruction or training to upgrade their 
understanding. One of the methods to train PWD was by introducing manual training as initiated by WHO following the declaration of Alma-Ata in 1978 to enhance the quality of life in their multidisciplinary activities (Idris, 2016). Manual skills of PWD can also be improved by performing manual tasks through haptic and sound interaction using a Multimodal Guidance System (MGS) that provides robotic assistance (Covarrubias et al., 2014). It was believed that visual representation was one of the ways to improve people with general disabilities (Kroesbergen and Van Luit, 2003). A study conducted on moderate intellectual disabilities revealed that both static photographs and video prompting were effective in increasing the independent performance of the cooking task (Mechling and Gustafson, 2009).

Realizing the fact that PWD needs special instruments for empowering their economy, life and wellbeing, a PWD-friendly module of bakery products has been developed to facilitate their knowledge and skills in the field. The development of this module is in line with one of the objectives of the establishment of community-based rehabilitation (CBR) to maximize the ability of PWD to become active contributors to society and the community. So far, there are inadequate resources specifically created for PWD as a guideline for them to practice bakeries. A review of training manuals from $\mathrm{WHO}$ and $\mathrm{CBR}$ revealed that very limited information was purposely created to tackle this group condition (Raja et al., 2020). Thus, this study was aimed to develop special resource material for PWD in the field of bakery practices in which they can use it without requiring ongoing assistance or at least with minimum assistance.

\section{Materials and methods}

\subsection{Content development}

The module on bakeries products was designed by our research team at the Faculty of Fisheries and Food Science, Universiti Malaysia Terengganu. The content was specifically outlined for four different types of bread or bakery products which include red bean bun, "paung" bread, pizza bread and sausage bread. All the modules have been reviewed by our research team many times in order to achieve interesting and easy-to-understand content that suits the capabilities of the respondents.

The content was divided into two general subtopics; preparation of materials and production procedure for each of the bread. Although the ingredients used and procedures involved at the early stage of making dough were similar, depending on the types of bread, the furnishing stage might differ between them. For each raw material, it was represented by a picture with packaging and label. Instead of using numbers as commonly stated in most teaching materials. These modules were designed to use a cup and spoon as the standard measurement. The conversion of units was implemented from metric units to appropriate sizes of cups and spoons. In fact, cups and spoons of different colours were used to represent different quantities of weights or volumes. Repetition of the same colour and size of cup or spoon was applied in the case where the measurement had more than one unit. The function of ingredients was explained in the form of text which can help those to understand more about the ingredients. The formulation given in the modules were based on the weight of $1 \mathrm{~kg}$ of bread flour.

In terms of the process procedure, all the steps come with instructions and pictures of the specific activity. It is important to make sure that no missing was made even a single step of the workflow. All the equipment involved in the production process were pictured in the module. This module emphasizes more on pictorial references rather than the description in text form.

\subsection{Revision and consolidation of module}

Before the module development can take place, a form of product development must be implemented first. This is done to find the best dough formulation and to ensure that it can be used in various types of bread products. The formulation developed has been tried in the kitchen to check for its stability once frozen and also properties of baking quality. The best formulations were selected based on their good properties in which they can maintain an appetizing appearance after baking or reheating them. This is to make sure that the products produced have commercialization value to be sold not only fresh but also as frozen products. The content and the presentation of each picture inserted in the module need to be revised to make it easier to understand. The pictures have to be coloured and suitable enough in size in that not too much information is placed on a single page of the module.

\subsection{Feasibility and acceptability testing}

\subsubsection{Ethical approval}

This project was approved by the Research Ethics Committee of Universiti Malaysia Terengganu with the reference approval number UMT/JKEPM/2020/50.

\subsubsection{Instruments: personal information form}

The respondents were chosen among PWD at the CBRs (Seberang Takir and Gong Badak), parents and staff members at both rehabilitation centres. No personal information was taken, however, the age of the PWD 
who participated was from 18 to 45 years old.

\subsubsection{Instruments: feasibility and acceptability questionnaire}

The questionnaire used to measure the feasibility and acceptability of the PWD-friendly module was adapted from Salihah et al. (2017). Respondents were required to answer all the online questions provided by ticking appropriate answers accordingly. The questionnaire is a 10 -item scale developed in the Malay language to suit the respondents' capability of understanding. The score is rated on a 5-point Likert scale ranging from 1 (strongly agree) to 5 (strongly disagree). The lower the score, the better were the feasibility and acceptability levels. Questions 1 to 3 were used to measure the feasibility of the module such as the colour scheme and language used. Questions 4 to 10 on the other hand were used to assess the acceptability of the module including skills and knowledge enhancement, user-friendly level and how attractive the module is to an individual's attention.

\subsection{Sampling and sample size}

The respondents were chosen based on the PWDs that were previously screened for their health status and participated in a series of bakery workshops. The conditions required to be involved in this project include that they must have a good level of health status without any critical illness such as diabetes, high blood pressure, heart disease and asthma. In addition, they need to be able to take care of themselves in terms of basic things in daily life such as eating and drinking, wearing clothes, using the toilet and others. Overall, thirty respondents participated in this survey. There were ten PWDs from two different CBRs in the district of Kuala Nerus, Terengganu was selected and participated in the project. Meanwhile, the other twenty respondents were selected from either their parents or CBR staff who were directly involved as a guide along with the workshop activities.

\subsection{Data collection}

Ten questions were prepared using Google Form and the link for the questions were given through online WhatsApp messenger. The chosen respondents (including their parents and CBR staff members) need to answer the questions after all the PWD have attended all the workshops. Due to the questionnaire was referring to the module provided, thus CBR staff eligible to respond because they were directly monitoring the PWD along with the workshop. While in this case their parent was considered to be the most understanding people about their child's needs. Just as the PWD constraints in the understanding method of delivery, they also found it difficult to understand the questionnaires by themselves.
For some PWD that are illiterate, CBR staff have to interview the PWD and read the questions carefully to help them understand the questions for choosing their responses.

\subsection{Data analysis}

All socio-demographic data were analysed descriptively and presented as frequencies and percentages. Each item was also analysed descriptively in order to examine the feasibility and acceptability of the PWD-friendly modules among the respondents. This was carried out by determining the number of respondents who answered in each Likert scale (n) and the corresponding percentage. For the final outcomes, those who chose Strongly Agree or Agree are collectively considered as agreeing and satisfied with its question. The opposite was true for Strongly Disagree or Disagree answers.

\section{Results}

The findings that were obtained from this study have been presented in Table 1 and Table 2, respectively. Table 1 described the design of the module development. While Table 2 described the result of the feasibility and acceptability of the PWD-friendly module.

\subsection{Functionality of the PWD-friendly module}

The PWD-friendly module is divided into three sections which have been summarized in Table 1 . The first section is the front page showing the picture of the final product where it provides information and gives perception on the product they are going to produce. This picture is expected to attract them and enthuse them to learn about producing the product. The second section is focusing on the preparation of ingredients. On the first page, pictures of all ingredients are presented as an overview of the ingredients they are going to use. The following pages are pictures of each ingredient which are arranged accordingly following the steps of preparation together with the amount required. To assist PWD candidates in measuring the weight of each ingredient, the amount was converted from grams into cups and spoons, based on the size and colour for the classification. For example, to measure salt which was originally around $16 \mathrm{~g}$, it was converted into a total of 1 white tablespoon (TBSP) and 1 white teaspoon (TSP). Other measurements include 1 yellow cup equal to 1 cup, 1 green cup equal to $1 / 3$ cup and 1 blue cup equal to $1 / 2$ cup. The importance of each ingredient is also stated at the bottom of the picture to assist the teacher/staff or parents if they want to explain to PWD during the preparation session. The last part of the module is the making process section. A concept of flow diagram has 
Table 1. Functionality of the module in improving knowledge and skills.

\begin{tabular}{cl}
\hline Component & \multicolumn{1}{c}{ Description } \\
\hline Front Page & $\begin{array}{l}\text { A picture of the bakery product to be produced so that the PWD can expect their final } \\
\text { product would be. }\end{array}$ \\
\hline $\begin{array}{l}\text { The amount of ingredients is measured by converting grams into cups and spoons which } \\
\text { are classified based on colour and size. For example, to measure salt which was } \\
\text { originally around } 16 \text { grams, it was converted into a total of } 1 \text { white tablespoon (TBSP) } \\
\text { and 1 white teaspoon (TSP). } \\
\text { ingredients }\end{array}$ & $\begin{array}{l}\text { Other measurements: } \\
1 \text { yellow cup }=1 \text { cup }\end{array}$ \\
& $\begin{array}{l}1 \text { green cup }=1 / 3 \text { cup } \\
1 \text { blue cup }=1 / 2 \text { cup. }\end{array}$ \\
& $\begin{array}{l}\text { The arrangement of pages are following the steps of the making procedure. } \\
\text { The concept of a flow diagram has been used to show the process. Pictures and arrows } \\
\text { are used to direct PWD on the steps. } \\
\text { Measurement of dough is standardized by rolling dough in a } 40 \times 30 \text { cm sized tray until } \\
\text { the dough spreads evenly filling the tray. A specific round cutter is used for each product } \\
\text { to cut the dough in the tray in order to get the right mass amount of dough. The cutter is } \\
\text { numbered to ease the process. Timing for a certain process like kneading and baking is } \\
\text { labelled by showing a timer consisting of hour, minute and seconds. }\end{array}$ \\
\hline
\end{tabular}

Table 2. Degree of responses on feasibility and acceptability of PWD-friendly modules

\begin{tabular}{|c|c|c|c|c|c|c|}
\hline & \multirow{2}{*}{ Statement } & \multicolumn{5}{|c|}{ Response, n (\%) } \\
\hline & & Strongly & Agree & Unsure & Disagree & Strongly \\
\hline 1 & PWD-friendly modules are easy to use. & $\begin{array}{c}25 \\
(83.3)\end{array}$ & $\begin{array}{c}5 \\
(16.7) \\
\end{array}$ & & & \\
\hline 2 & $\begin{array}{l}\text { The language used in the PWD-friendly module is simple and } \\
\text { easy to understand. }\end{array}$ & $\begin{array}{c}19 \\
(63.3)\end{array}$ & $\begin{array}{c}11 \\
(36.7)\end{array}$ & & & \\
\hline 3 & The colour scheme of the PWD-friendly module is attractive. & $\begin{array}{c}19 \\
(63.3) \\
\end{array}$ & $\begin{array}{c}10 \\
(33.3) \\
\end{array}$ & $\begin{array}{c}1 \\
(3.3) \\
\end{array}$ & & \\
\hline 4 & PWD-friendly modules help to increase knowledge. & $\begin{array}{c}24 \\
(80)\end{array}$ & $\begin{array}{c}6 \\
(20) \\
\end{array}$ & & & \\
\hline 5 & PWD-friendly modules help to increase skills. & $\begin{array}{c}24 \\
(80)\end{array}$ & $\begin{array}{c}6 \\
(20) \\
\end{array}$ & & & \\
\hline 6 & A PWD-friendly module is beneficial to me. & $\begin{array}{c}25 \\
(83.3) \\
\end{array}$ & $\begin{array}{c}5 \\
(16.7) \\
\end{array}$ & & & \\
\hline 7 & PWD-friendly modules attract my attention. & $\begin{array}{c}21 \\
(70)\end{array}$ & $\begin{array}{c}8 \\
(26.7) \\
\end{array}$ & $\begin{array}{c}1 \\
(3.3)\end{array}$ & & \\
\hline 8 & I would like to use a PWD-friendly module in the future. & $\begin{array}{c}23 \\
(76.7) \\
\end{array}$ & $\begin{array}{c}7 \\
(23.3) \\
\end{array}$ & & & \\
\hline 9 & $\begin{array}{l}\text { Overall, I think PWD-friendly modules are very helpful in } \\
\text { bakery production. }\end{array}$ & $\begin{array}{c}27 \\
(90)\end{array}$ & $\begin{array}{c}3 \\
(10) \\
\end{array}$ & & & \\
\hline 10 & I would recommend a PWD-friendly module to other people. & $\begin{array}{c}24 \\
(80)\end{array}$ & $\begin{array}{c}6 \\
(20) \\
\end{array}$ & & & \\
\hline
\end{tabular}

been used, but showing a real picture of ingredients, apparatus and equipment to be used along the process. To direct PWD to add salt first into the mixing bowl, a picture of 1 white TBSP and 1 TSP of salt are placed with an arrow showing the direction to a picture of the mixing bowl of a mixer.

The following steps are using the same concept but replace the picture of salt with other ingredients required into the mixing bowl. The kneading process is started by showing a timer picture which consists of an hour, minute and second. Other processes are dough testing which is called the Windowpane test, dough rolling and cutting, pan preparation, dough proofing and baking. The rolling and cutting processes of dough are important to ensure the amount of dough is right with consistent weight for each bakery product. This is carried out by rolling the dough in a $40 \times 30 \mathrm{~cm}$ sized tray to ensure PWD can produce a consistent thickness of the dough. After that, a respective round cutter is used to produce the right amount of dough with a consistent weight. For example, $100 \mathrm{~g}$ of dough is used to make pizza and is produced by using a number 7 round cutter. Other processes can be understood directly by showing pictures 
of the process.

\subsection{Feasibility and acceptability}

The feasibility and acceptability of the PWDfriendly module were assessed using a questionnaire that consists of 10 questions. Thirty respondents were involved in this study consisting of PWD candidates, staff of CBR and parents of PWD. Some PWD may need their parents or CBR staff to help in reading, understanding and answering the questionnaire. Most of the answers were either Strongly Agree or Agree showing that they agreed on the convenience and language used in the module where the score was $100 \%$. The result of the responses was presented in Table 2 .

The feasibility component of the PWD-friendly module includes the easiness to use the module, simplicity and easiness to understand the language, and the attractiveness of the colour scheme used. Approximately $83.3 \%$ of the PWD candidates score Strongly Agree; however, only $16.7 \%$ score Agree on the ease to use the designed module with a total of $100 \%$. Similarly, the perception of the PWD on the language and colour scheme used to score a higher value (63.3\%) for Strongly Agree than the score for Agree. The level of the candidate's understanding might also be supported by the screening process that was previously done during the selection of the candidates. In addition, the acceptability component of the PWD-friendly module includes the knowledge and skill enhancement, benefit gain and user-friendly level, the attractiveness of the module to the candidates, the potential module used for bakery production and the potential of the module to be recommended to other people for future use. Generally, this module was user friendly $(100 \%)$, helpful $(100 \%)$ and recommended to be used by other people (100\%).

\section{Discussion}

The PWD-friendly module designed for the production of bakeries could help the disabled to be exposed to the vocational program on how to bake pastries. Furthermore, with concepts memorised and critical life skills mastered, the students will be ready for a workplace that values their proficiency but also appreciates their differences. This technique adhered to the fundamental principles of special education which are required to determine the strength of each individual and the method that match their skills and interest (Srivastava, 2020). For instance, in this module, to teach the students recipes, a colour system using red, white, green and yellow labels might help the students memorise the measurements. As suggested, it is helpful for persons with intellectual developmental disabilities (IDDs) to be adapted with visualization design for better understanding (Wu et al., 2019). According to Dunn (2020), students with high incidence disabilities can effectively respond by visualization in order to motivate them to make meaningful and enhance interaction with the text.

Unlike normal students, those with disabilities should be given extra time to learn and practice new skills. During the training session, each PWD was assigned with one instructor to assist and evaluate their performance. The option must be given for them in somewhat different tasks that need particular kinds of instructions (Vaughn et al., 2015). These modules have considered some particular aspects suggested by GarciaCarrian et al. (2018) to maximize students' learning opportunities for disabilities including the role of adults and preparation of the activity.

In this program, from a technical standpoint, everybody is learning a skill. But more than that, this is truly an incredible opportunity for the students to be able to participate in the major activity of every adult's life, which is doing work. The students are taught the same skills as a standard program but in a different way, in a way that is achievable for them. Where the goal is for everybody to be able to go to work. A study conducted by Lindsay et al. (2012) revealed that skill development during training programs for PWD have increased their self-confidence as well as their practical and social skills. One of the approaches to tackle the unemployment problem of PWD is through community economic development (CED) which addresses a holistic and participatory way (Parmenter, 2011).

The development of these modules for PWD could help them to increase their employability by improving their pre-vocational skills, self-expression. Apart from that, it may help to increase motivation, enabling them to live independently and contribute to the development of the country. This will indirectly contribute to the achievement of the strategic objective of the "OKU Action Plan 2016-2020" which is to increase the opportunity for the disabled to work on their own by participating in entrepreneurship and economic empowerment programs.

\section{Conclusion}

PWD's involvement in various aspects of the country's economic development is an inspiration to the government so that no party is marginalized in society. By developing a PWD-friendly module, it is hoped that it can be used as a useful reference in developing their skills in many bakery products. This module not only benefits those who are directly involved with the workshop but also can be sustainably used by other 
PWDs in their respective CBR as a training module.

\section{Conflict of interest}

The authors declare no conflict of interest.

\section{Acknowledgements}

The authors thank the Universiti Malaysia Terengganu for the financial support on this project through Knowledge and Technology Assimilation Grant (KTAG) 2019, reference number 58902. We gratefully thank Ziq Bakery and Cake Sdn. Bhd. as well as community-based rehabilitation (CBR) of Seberang Takir and Gong Badak, Kuala Nerus, Terengganu for technical support and providing facilities for training and workshop. Special thanks also to all members of our group team including FPSM lecturers and lab staffs for hard-working in carrying out activities throughout the project period.

\section{References}

Babulal, V. (2017). Malaysia's Disabled still Marginalized, Says Suhakam, New Straits Times, Retrieved on January 20, 2021 from https:// www.nst.com.my/news/nation/2017/12/311353/ malaysias-disabled-still-marginalised-sayssuhakam\#

Covarrubias, M., Gatti, E., Bordegoni, M., Cugini, U. and Mansutti, A. (2014). Improving manual skills in persons with disabilities (PWD) through a Multimodal Assistance System. Disability and Rehabilitation Assistive Technology, 9(4), 335-343. https://doi.org/10.3109/17483107.2013.799238

Department of Social Welfare. (2009). Dasar Orang Kurang Upaya. Retrieved on January 18, 2021 from http://www.jkm.gov.my/index.php?

option $=$ com_content\&view $=$ article $\& i d=88 \&$ Itemid $=$ 1017\&langen [In Bahasa Malaysia].

Dunn, L.A.C. (2020). Using elements of a screenplay to promote visualization and increase reading comprehension in secondary students with high incidence disabilities. Reading and Writing Quarterly: Overcoming Learning Difficulties, 37(5), 395-412. https:// doi.org/10.1080/10573569.2020.1839611

Garcia-Carrian, R., Roldon, S.M. and Campos, E.R. (2018). Interactive learning environments for the educational improvement of students with disabilities in special schools. Frontiers Psychology, 9, 1744. https://doi.org/10.3389/fpsyg.2018.01744

Idris, F.H. (2016). Community based rehabilitation solution for global problems in improving quality of life of persons with disability Indonesia's experience 1985-2016, presented at the $2^{\text {nd }}$ International Multidisciplinary Conference 2016. Indonesia: Universitas Muhammadiyah Jakarta.

Jackson, L.B., Ryndak, D.L. and Wehmeyer, M.L. (2009). The dynamic relationship between context, curriculum, and Student learning: A case for inclusive education as a research-based practice. Research and Practice for Person with Severe Disabilities, 33(4), 175-195. https://doi.org/10.2511/ rpsd.33.4.175

Kroesbergen, E.H. and Van, Luit J.E.H. (2003). Mathematics interventions for children with special educational needs - A meta-analysis. Remedial and Special Education, 24(2), 97-114. https:// doi.org/10.1177/07419325030240020501

Lindsay, S., Adams, T., Mcdougall, C. and Sanford, R. (2012). Skill development in an employmenttraining program for adolescents with disabilities. Disabilities and Rehabilitation, 34(3), 228-227. https://doi.org/10.3109/09638288.2011.603015

Mechling, L.C. and Gustafson, M. (2009). Comparison of the effects of static picture and video prompting on completion of cooking related tasks by students with moderate intellectual disabilities. Exceptionality, 17(2), 103-116. https:// doi.org/10.1080/09362830902805889

Parmenter, R.T. (2011). Promoting training and employment opportunities for people with intellectual disabilities: International experience. Employment Working Paper No. 103. Skills and Employability

Raja, K., Gupta, S., Mathew, J. and Rao, P. (2020). Development of training manuals for community disability workers. Physiotherapy, 14(1), 37-40. https://doi.org/10.4103/PJIAP.PJIAP_19_19

Salihah, N., Lua, P.L., Ahmad, A. and Shahril, M.R. (2017)."CANDITM": A Malaysian-tailored dietary smartphone App for cancer patients and survivors. Malaysian Journal of Public Health Magazine, 2, 32 -40 .

Social Welfare Department. (2021). Obtaining facilities, welfare and health care, retrieved on March 17, 2021 , https://www.malaysia.gov.my/portal/ content $/ 30155$

Srivastava, P. (2020). Verbal Learning. Impact of PWD Act 1995 on education and rehabilitation of PWD disability among primary school students. International Journal of Medical Science and Pathology, 1(10), 4-9.

Vaughn, S., Danielson, L., Zumeta, R. and Holdheide, L. (2015). Deeper learning for students with 
disabilities. Deeper Learning Research Series, August 2015. Retrieved on January 18, 2021 from https://files.eric.ed.gov/fulltext/ED560790.pdf

Wahab, H.A. and Ayub, Z.A. (2016). Persons with Disabilities Act 2008: The economic promises for people with disabilities? International Journal of Economics and Financial Issues, 6(7S), 313-319.

Wu, K., Tanis, S. and Szafir, D.A. (2019). Designing communicative visualization for people with intellectual developmental disabilities. USA: University of Colorado Boulder. https:// doi.org/10.31219/osf.io/zbjhr 